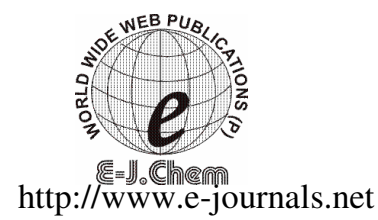

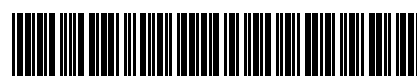

ISSN: 0973-4945; CODEN ECJHAO

E-Journal of Chemistry 2010, 7(S1), S49-S54

\title{
UV Spectrophotometric Method for the Estimation of Itopride Hydrochloride in Pharmaceutical Formulation
}

\author{
K. R. GUPTA*, R. R. JOSHI, R. B. CHAWLA and S. G. WADODKAR \\ Department of Pharmaceutical Chemistry \\ SKB College of Pharmacy New Kamptee, Nagpur (MS)-441002, India \\ krishnargupta@rediffmail.com
}

Received 12 January 2010; Accepted 5 March 2010

\begin{abstract}
Three simple, precise and economical UV methods have been developed for the estimation of itopride hydrochloride in pharmaceutical formulations. Itopride hydrochloride in distilled water shows the maximum absorbance at $258.0 \mathrm{~nm}$ (Method A) and in first order derivative spectra of the same shows sharp peak at $247.0 \mathrm{~nm}$, when $\mathrm{n}=1$ (Method B). Method C utilises area under curve (AUC) in the wavelength range from $262.0-254.0 \mathrm{~nm}$ for analysis of itopride hydrochloride. The drug was found to obey BeerLambert's law in the concentration range of $5-50 \mu \mathrm{g} / \mathrm{mL}$ for all three proposed methods. Results of the analysis were validated statistically and recovery studies were found to be satisfactory.
\end{abstract}

Keywords: Itopride hydrochloride, UV spectroscopy, Derivative spectroscopy, Area under curve.

\section{Introduction}

Itopride hydrochloride $^{1}$ (ITH) is a gastroprokinetic agent. It increases the release of acetylcholine (Ach) through dopamine $\mathrm{D}_{2}$ receptor antagonistic action, resulting in enhancement of gastrointestinal motility. Chemically it is $N$-[4-[2-(dimethylamino)ethoxy]benzyl]-3,4dimethylbenzamide hydrochloride (Figure 1). Literature survey reveals HPLC determination of itopride hydrochloride in tablet formulation ${ }^{2,3}$, RP-HPLC in human serum $^{4,5,6}$. Extractive spectrophotometric ${ }^{7}$ determination of itopride hydrochloride in bulk and formulation which involves the formation of coloured chloroform extractable complex of drug with bromocresol green in acidic medium. The complex in chloroform has showed absorption maxima at $419.8 \mathrm{~nm}$, spectrophotometric estimation based on coloured complex with methyl orange ${ }^{8}$, HPTLC ${ }^{9}$. The above method requires costlier solvents or tedious extraction procedure before its application. Hence an attempt has been made to develop new uv methods for its estimation in pharmaceutical formulation with good accuracy, simplicity, precision and economy so as to utilises it in routine analysis of the drug. 
<smiles>COc1ccc(C(=O)NCc2ccc(OCCN(C)C)cc2)cc1OC</smiles>

\section{Experimental}

Figure 1. Structure of itopride hydrochloride $\mathrm{HCl}$

A Shimadzu UV 1100 series Spectrophotometer was used with $1 \mathrm{~cm}$ matched quartz cells.

\section{Standard solutions}

A standard stock solution of ITH in distilled water was prepared having a concentration $600 \mu \mathrm{g} / \mathrm{mL}$. A $5.0 \mathrm{~mL}$ portion of stock solution was further diluted with water in a $100.0 \mathrm{~mL}$ volumetric flask up to mark to get final concentration $30 \mu \mathrm{g} / \mathrm{mL}$.

The standard solution of ITH $(30 \mu \mathrm{g} / \mathrm{mL})$ was scanned in the range of $400-200 \mathrm{~nm}$ (Method A) in $1.0 \mathrm{~cm}$ cell against solvent blank and spectra was recorded, the absorbance maxima was observed at $258.0 \mathrm{~nm}$ (Figure 2). The drug followed the Beer's- Lambert's law in concentration range of $5-50 \mu \mathrm{g} / \mathrm{mL}$ for all three methods and correlation coefficient was $0.9999,0.9998$ and 0.9999 for Method A, B and C respectively. Using the A $(1 \%, 1 \mathrm{~cm})$ of ITH the concentration of sample solutions can be determined.

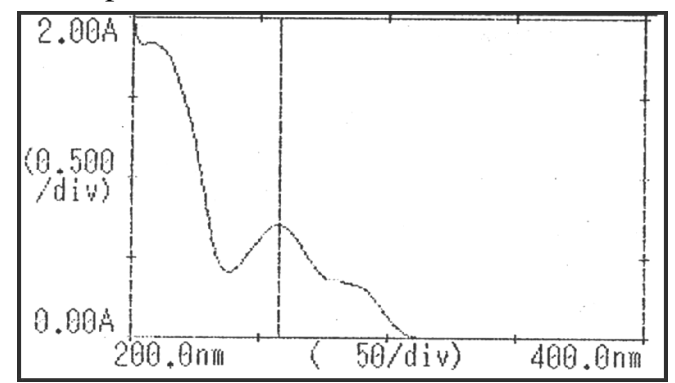

Figure 2. Zero order spectrum of itopride hydrochloride in water

The first order derivative spectra at $n=1$ (method B) showed a sharp peak at $247.0 \mathrm{~nm}$ (Figure $3)$. The absorbance difference calculated at $n=1(\mathrm{dA} / \mathrm{d} \lambda)$ is calculated by the inbuilt software of the instrument which was directly proportional to the concentration of the standard solutions. The calibration curve of $\mathrm{dA} / \mathrm{d} \lambda$ against concentration of the drug showed linearity, which are used for the estimation of the drug. The AUC (Area under Curve) method (method C) involves the calculation of integrated value of absorbance with respect to the wavelength $\lambda 1$ and $\lambda 2$.

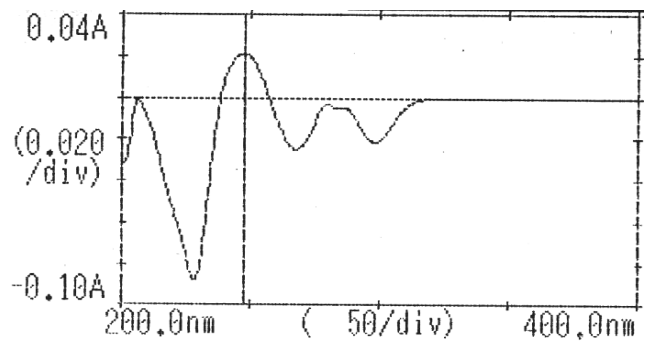

Figure 3. First order spectrum $(\mathrm{N}=1)$ of itopride hydrochloride in water 
Area calculation processing item calculates the area bound by the curve and the horizontal axis. The horizontal axis was selected by entering the wavelength range over which the area has to be calculated. The wavelength range from 262.0-254.0 nm was selected which showed good linearity between area under curve and concentration. Different concentration of the standard drug $(5-50 \mu \mathrm{g} / \mathrm{mL})$ were prepared and scanned in the spectrum mode from the wavelength range 400-200 nm (Figure 4). Calibration curve was plotted as area under curve against concentration, and the estimation of the drug was done using the curve.

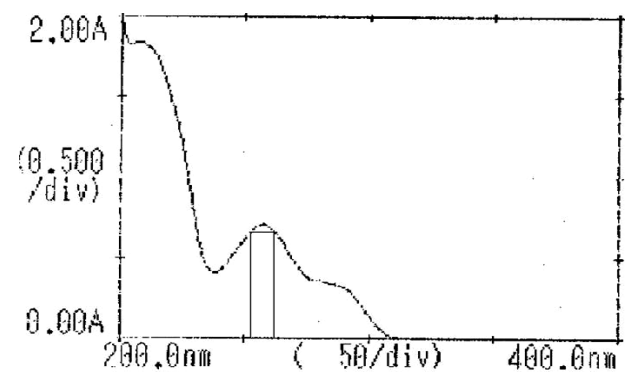

Figure 4. Area under curve of itopride hydrochloride in water

\section{Sample solutions}

An accurately weighed quantity of tablet powder equivalent to about $30 \mathrm{mg}$ ITH was transferred to $50.0 \mathrm{~mL}$ volumetric flask, sonicated for $15 \mathrm{~min}$ with distilled water and diluted up to the mark with distilled water to get a stock solution of $600 \mu \mathrm{g} / \mathrm{mL}$. The solution was then filtered through Whatmann filter paper (no. 41). A $5.0 \mathrm{~mL}$ of the filtrate was further diluted in a $100.0 \mathrm{~mL}$ volumetric flask with distilled water to get concentration of $30 \mu \mathrm{g} / \mathrm{mL}$ of ITH (on labelled claim basis). The absorbance of the resulted solution was read and the amount of ITH was calculated by taking A $(1 \%, 1 \mathrm{~cm})$ at $258.0 \mathrm{~nm}(\operatorname{method} \mathrm{A})$, by first order derivative spectroscopy at $247.0 \mathrm{~nm}$ (method B) and by Area under Curve (AUC) (Method C). Calculation was done by using following formulae for method A, for method B and $\mathrm{C}$ comparison with standard for its derivative absorbance and area were done respectively.

By A $(1 \%, 1 \mathrm{~cm})$

$$
\% \text { of labelled claim }=\frac{\text { Absorbance } \times \text { Dilution factor } \times \text { Avg wt }}{\mathrm{A}(1 \%, 1 \mathrm{~cm}) \times \mathrm{Wt} \text { taken } \times \text { Label claim }} \times 100
$$

Table 1. Optical characteristics and other parameters

\begin{tabular}{lccc}
\hline Parameters & Method A & Method B & Method C \\
\hline$\lambda_{\text {Max }}, \mathrm{nm} /$ wavelength range Beer- & 258.0 & 247.0 & $262-254.0$ \\
Lambert's range, $\mu \mathrm{g} / \mathrm{mL}$ & $5-50$ & $5-50$ & $5-50$ \\
Correlation coefficient, $\mathrm{r}$ & 0.9999 & 0.9998 & 0.9999 \\
Regression equation Y = mx + c & & & \\
a. Slope, m & 0.0338 & 0.001 & 0.25923 \\
b. Intercept, c & 0.00057 & 0 & 0.00638 \\
LOD & 0.5022 & 1.5068 & 0.2511 \\
\hline
\end{tabular}

Where, $X$ is concentration in $\mu \mathrm{g} / \mathrm{mL} \& Y$ is absorbance unit, $A$ is zero order derivative spectrum method with $n=0, B$ is first order derivative spectrum method with $n=1, C$ is the AUC method. 
Table 2. Estimation itopride hydrochloride in tablet formulation

\begin{tabular}{ccccc}
\hline Method & Tablet formulation & \% Label claim & S. D., ${ }^{*}$ & S. E. $^{*}$ \\
\hline \multirow{2}{*}{ A } & T1 & 100.25 & 0.58 & 0.25 \\
& T2 & 100.11 & 0.53 & 0.24 \\
B & T1 & 100.32 & 0.60 & 0.26 \\
& T2 & 100.02 & 0.53 & 0.23 \\
C & T1 & 99.69 & 0.29 & 0.14 \\
& T2 & 99.40 & 0.41 & 0.18 \\
\hline
\end{tabular}

Where, $A$ is zero order spectrum method, $B$ is first order derivative spectrum method with $n=1, C$ is the AUC method. TI and T2 are two different brands of tablet formulations. ${ }^{*}$ The results are the mean of five readings $(n=5)$.

\section{Results and Discussion}

All the methods A, B and C for the estimation of itopride hydrochloride in tablet dosage form were found to be accurate, simple and reproducible. Beer-Lambert's law was obeyed in the concentration range of $5-50 \mu \mathrm{g} / \mathrm{mL}$ in all three methods. The values of standard deviation were satisfactory and the recovery studies were close to $100 \%$. All these methods were validated according to ICH guidelines for accuracy, precision, stability, linearity and range and ruggedness

\section{Accuracy}

Recovery studies were carried out at four different levels by adding the pure drug (5.04, $10.08,15.12$ and $20.16 \mathrm{mg}$ ) to previously analyzed tablet powder sample. From the amount of drug found, percentage recovery was calculated and the results of analysis of recovery studies are shown in Table 3a.

Table 3a. Recovery study data (Accuracy)

\begin{tabular}{ccccccc}
\hline Method & $\begin{array}{c}\text { Tablet } \\
\text { formulation }\end{array}$ & $\begin{array}{c}\text { Amount of pure } \\
\text { drug added, mg }\end{array}$ & $\begin{array}{c}\text { Amount of pure } \\
\text { drug recovered, mg }\end{array}$ & $\begin{array}{c}\% \\
\text { Recovery }\end{array}$ & S.D., \pm S.E \\
\hline \multirow{4}{*}{$\mathrm{A}$} & & 5.04 & 5.05 & 100.20 & & \\
& $\mathrm{~T} 1$ & 10.08 & 10.10 & 100.20 & & \\
& & 15.12 & 15.24 & 100.79 & 0.63 & 0.32 \\
& & 20.16 & 20.01 & 99.26 & & \\
$\mathrm{~B}$ & $\mathrm{~T} 1$ & 5.04 & 5.01 & 99.40 & & \\
& & 10.08 & 10.04 & 99.60 & & \\
& & 15.12 & 15.13 & 100.07 & 0.50 & 0.25 \\
& & 20.16 & 20.27 & 100.54 & & \\
$\mathrm{C}$ & $\mathrm{T} 1$ & 10.04 & 5.04 & 100.00 & & \\
& & 15.12 & 9.96 & 99.81 & & 0.12 \\
\hline
\end{tabular}

Where, $A$ is zero order spectrum method, $B$ is first order derivative spectrum method with $n=1, C$ is the AUC method. T1 is the brand of the tablet formulation. *The results are the mean of three readings at each level of recovery.

\section{Precision}

\section{Inter-day precision}

It was done by analysing the solutions by same analyst on alternate days till $5^{\text {th }}$ day. The $\%$ RSD is shown in Table $3 b$. 


\section{Intra day precision}

It was done by analysing the solutions by same analyst within a day. The \% RSD is shown in Table $3 b$.

Table 3b. Summary of validation parameters

\begin{tabular}{|c|c|c|c|}
\hline \multirow{2}{*}{ Parameters } & \multicolumn{3}{|c|}{ Results } \\
\hline & Method A & Method B & Method C \\
\hline \multicolumn{4}{|l|}{ Intra day precision } \\
\hline Amount found ${ }^{*}$ & $100.41 \pm 0.25$ & $100.52 \pm 0.05$ & $99.44 \pm 0.24$ \\
\hline RSD, \% & 0.25 & 0.05 & 0.24 \\
\hline \multicolumn{4}{|l|}{ Inter day precision } \\
\hline Amount found & $100.02 \pm 0.48$ & $100.52 \pm 0.05$ & $99.05 \pm 0.48$ \\
\hline RSD, \% & 0.48 & 0.05 & 0.48 \\
\hline Ruggedness, RSD\% & 0.35 & 0.82 & 0.24 \\
\hline
\end{tabular}

Where, $A$ is zero order spectrum method, $B$ is first order derivative spectrum method with $n=1, C$ is the AUC method. $\left.{ }^{(M e a n} \% \pm S . D\right)$

\section{Linearity and range}

Accurately weighed quantities of tablet powder equivalent to 80, 90, 100, 110 and $120 \%$ of label claim of ITH were taken in a series of $50 \mathrm{~mL}$ volumetric flasks and dilutions were made as under sample solution. The graphs of \% label claim $v$ s. absorbance were plotted for method A (Zero order spectrum method) \& method B (first order derivative spectrum method) and \% label claim vs. area under curve was plotted for method C (AUC method). All the three methods were found to be linear.

Ruggedness

It was done by analysing the samples solutions by three different analysts. The \% RSD by proposed methods is shown in Table $3 b$.

\section{Stability}

The samples were kept under following conditions viz.

1) Refluxed for $3 \mathrm{~h}$ after addition of $30.0 \mathrm{~mL}$ of $0.5 \mathrm{~N} \mathrm{NaOH}$ (Alkali)

2) Refluxed for $3 \mathrm{~h}$ after addition of $30.0 \mathrm{~mL}$ of $0.5 \mathrm{~N} \mathrm{HCl}$ (Acid)

3) At $50{ }^{\circ} \mathrm{C}$ after addition of $30.0 \mathrm{~mL}$ of $6 \% \mathrm{H}_{2} \mathrm{O}_{2}$ for $24 \mathrm{~h}$ (Oxide $6 \%$ )

4) At $60{ }^{\circ} \mathrm{C}$ for $24 \mathrm{~h}$ (Thermal Degradation)

5) At $75 \%$ humidity for $24 \mathrm{~h}$ (Humidity)

6) At UV exposure for $24 \mathrm{~h}$ (UV)

7) Exposed to direct Sun Light for $6 \mathrm{~h}$ (Photochemical)

After the specified period, the results were analysed by proposed methods and are shown in Table 4. The present three methods have also been subjected to stress conditions to asses the stability of the drug under various conditions. Though conclusive evidence about its un-stability can be predicated from the results but it can be seen that drug was found to be susceptible to alkaline, oxide and humidity conditions as indicated by different percent label claim as compared to normal condition by proposed methods. 
Table 4. Results of specificity studies

\begin{tabular}{lccc}
\hline Sample & \multicolumn{3}{c}{ \% Label claim } \\
\cline { 2 - 4 } (Sample Treated) & Method A & Method B & Method C \\
\hline Alkali & 105.22 & 103.27 & 105.55 \\
Acid & 101.25 & 100.23 & 100.54 \\
Oxide 6\% & 92.98 & 90.29 & 92.85 \\
Thermal Degradation & 100.86 & 99.65 & 99.99 \\
Humidity & 96.56 & 95.93 & 96.36 \\
UV & 100.41 & 99.85 & 99.73 \\
Photochemical & 100.23 & 100.01 & 99.56 \\
\hline
\end{tabular}

\section{Conclusion}

From the statistical comparison of results, were found to satisfactory and validated. Hence these methods can be useful in the routine analysis of ITH in bulk drug and formulations.

\section{References}

1. James F/F R, Martindale, The Extra Pharmacopoeia, $33^{\text {th }}$ Ed., Pharmaceutical Press, London, UK, 1229.

2. Kaul N, Agrawal H, Maske P, Ramchandra Rao J, Mahadik K R and Kadam S S, $J$ Sep Sci., 2005, 28(13),1566-1576.

3. Dighe V V, Sane R T, Menon S N, Tambe H, Inamdar S and Pillai S, Indian Drugs, 2006, 43, 282-286.

4. Singh S S, Jain M, Shah H, Gupta S, Purav T, Ruchy S and Braj Bhushan L, $J$ Chromatogr B, 2004, 813, 247-254.

5. Singh S S, Jain M, Sharma K, Shah B, Vyas M, Thakkar P, Shah R, Singh S and Lohray B, J Chromatogr B, 2005, 818, 213-220.

6. Jing Ma, Li-Hua Yuan, Mei-Juan Ding, Jun Zhang, Qing Zhang, Qun-Wei Xu and Xue-Min Zhou, Pharmacological Research, 2009, 59(3), 189-193.

7. Hussainy , Smitha G, Areefulla S, Swamy P V and Appala R S, Int J Chem Sci., 2006, 4(3), 713-716.

8. Choudhary B, Goyal A and Khokra S, Int J Pharmacy Pharm Sci., 2009, 1, 159-162.

9. Suganthi A, karthikeyan R and Ravi T K, Indian Drugs, 2006, 43(10), 827-830. 


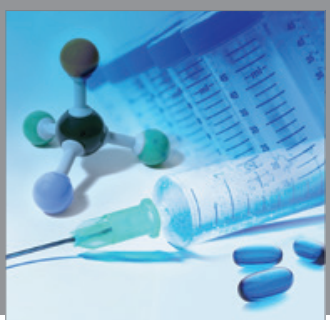

International Journal of

Medicinal Chemistry

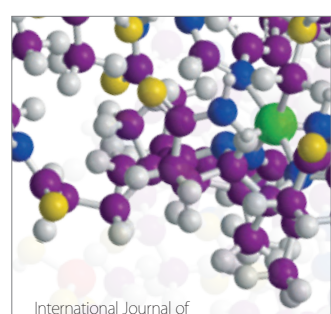

Carbohydrate Chemistry

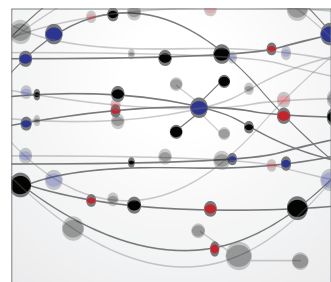

The Scientific World Journal
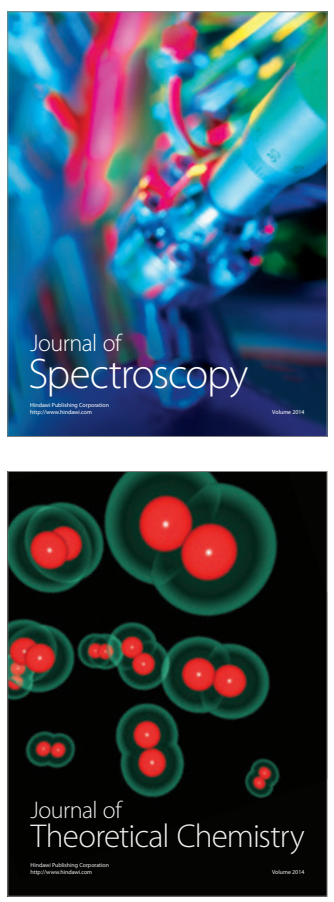
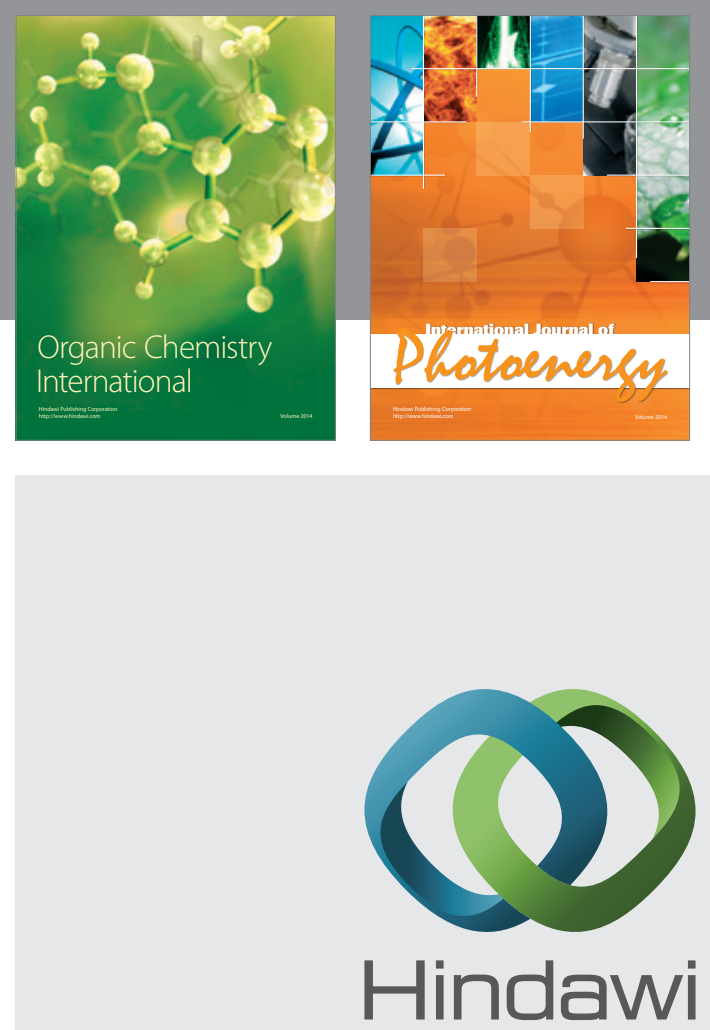

Submit your manuscripts at

http://www.hindawi.com
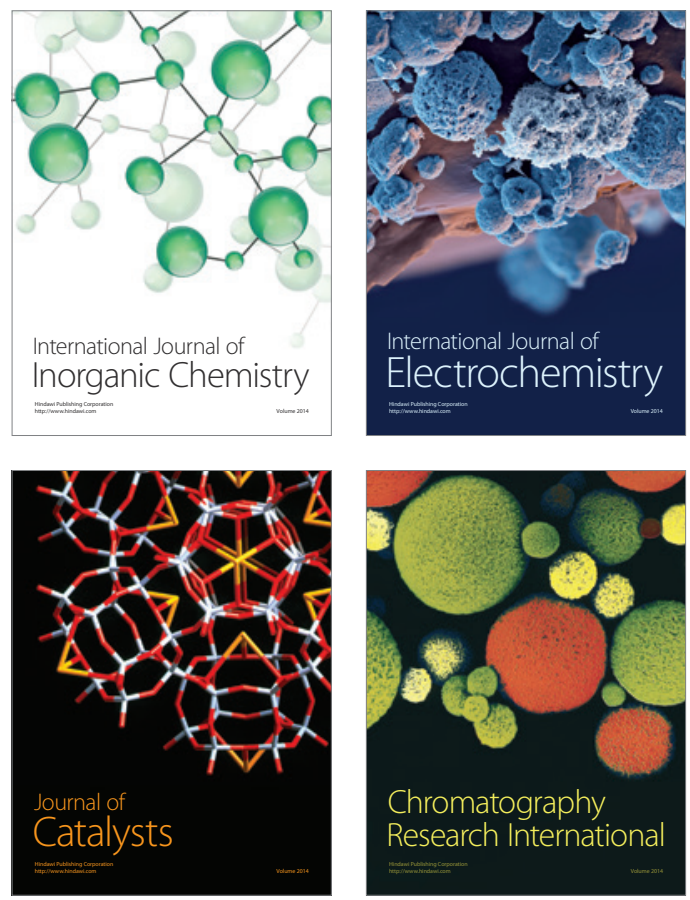
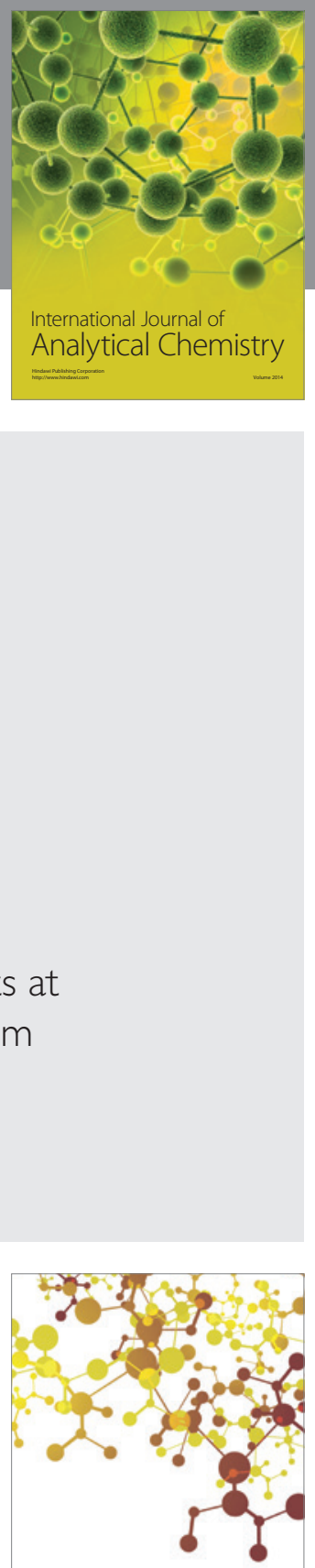

Journal of

Applied Chemistry
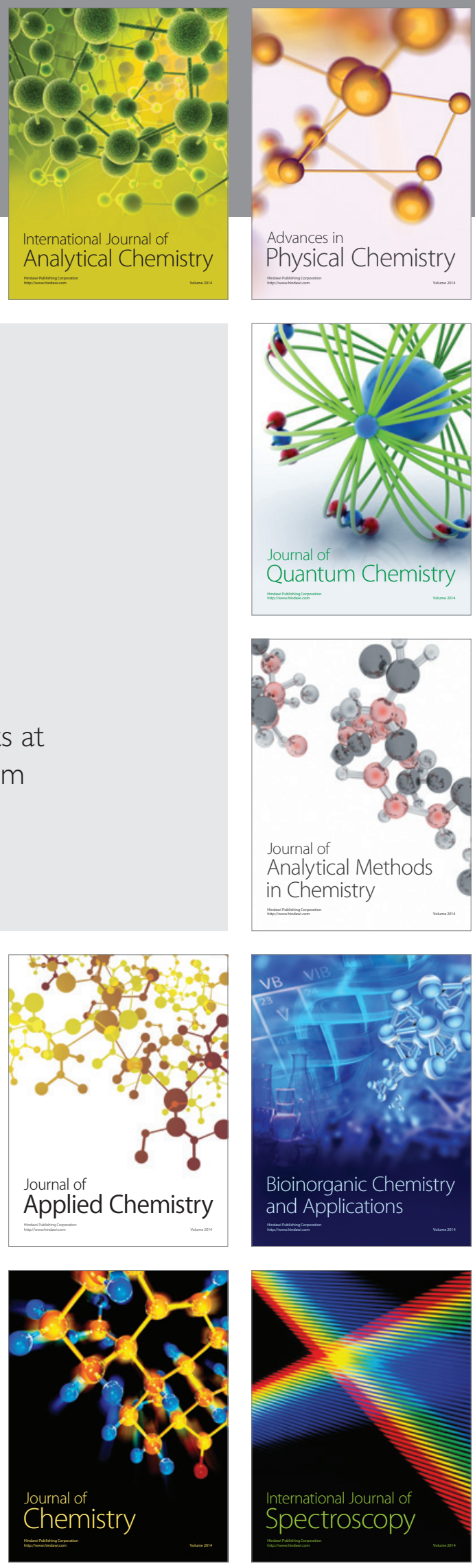